\title{
EL ENCANTAMIENTO: SOBRE UNA TRADUCCIÓN ANÓNIMA MANUSCRITA DE LA NOVELLA XLIV DE CASTI (ESTUDIO Y EDICIÓN DEL TEXTO) ${ }^{1}$
}

\author{
Ángeles ARCE MENÉNDEZ \\ Universidad Complutense de Madrid \\ arcea@filol.ucm.es
}

\section{RESUMEN}

Se publica por primera vez el texto inédito (Ms. 4084 de la BNM) de la traducción castellana de una de las novelas en verso de Giambattista Casti, abate libertino del Settecento italiano. El traductor, escondido en el anonimato a causa de la hipócrita censura del puritano siglo XIX español, resuelve un texto lleno de erotismo y sensualidad, que versifica en octavas la prosa de Boccaccio (Decameron IX, 10), para intentar la metamorfosis de una mujer en yegua en un encantamiento, que no podrá llevarse a cabo.

Palabras ClaVE: Giambattista Casti; Boccaccio; metamorfosis; encantamiento; novella.

\section{ABSTRACT}

The unknown text (Ms 4084 of the BNM) of the translation into Spanish of one of the verse novels of Giambattista Casti, libertine of the Italian Settecento is published for the first time. The translator, who remains anonymous because of the hypocritical censorship of the puritan Spanish XIX, solves an erotically charged sensual text, with a po-

\footnotetext{
${ }^{1}$ El trabajo se enmarca en el Proyecto de Investigación (HUM 2005-00042) financiado por el Ministerio de Ciencia y Tecnología: Texto y paratexto en las traducciones españolas de la literatura italiana (elaboración de un hipertexto de las traducciones literarias al castellano y al catalán: 1300-1939).
} 
etic version in octaves of Boccaccio (Decameron IX, 10), to attempt the metamorphosis of a woman into a mare in a 'bewitching' which will not take place.

KEY wORDS: Giambattista Casti; Boccaccio; metamorphosis; bewitching; novella.

En la Biblioteca Nacional de Madrid se conserva una traducción manuscrita decimonónica de una obrita italiana de finales del siglo XVIII, posiblemente obra de un copista, dada la extrema pulcritud de los folios sin tachaduras ni correcciones interlineales. El texto español -carente de portada y de cualquier otro dato referente al autor de la versión o al autor original, así como de lugar o fecha que hubiera servido para su identificación- consta de dos tomos, encuadernados con posterioridad y numerados de forma independiente $^{2}$, a los que acompaña, como epitexto, una carta autógrafa del 'donante' de los folios a los fondos de la biblioteca para evitar su pérdida ${ }^{3}$.

Es mi intención publicar por primera vez el texto castellano, inédito hasta ahora, de uno de los cuentos que forman parte de la colección titulada en italiano como Novelle galanti, del abate Giambattista Casti, escritor polémico nacido en los Estados Pontificios en la segunda década del Settecento ${ }^{4}$. Viajero incansable por las más importantes cortes europeas y tertulias mundanas, se hizo famoso por su anticonformismo con la Curia y, como buen representante del Illuminismo, por su espíritu crítico con la sociedad galante y la política contemporánea, actitud que, como podemos suponer, le acarreó no pocos sinsabores y problemas ${ }^{5}$.

Casti sufrió, de alguna manera, las consecuencias de la hipocresía y doble moral que imperaban en los círculos dieciochescos, y mientras dos de sus obras fueron incluidas en el Índice poco después de su muerte ${ }^{6}$, durante su vida estas obras gozaron de un enorme éxito tanto de editores, que escamoteaban la censura con ediciones apócrifas de mala calidad, como de público, fundamentalmente femenino, que asistía entusiasmado a las lecturas que el propio abate hacía, con una peculiar voz gangosa como consecuencia de la sífilis que contrajo después de un viaje por la península ibérica. La estructura de esas obras narrativas con métrica pautada de endecasílabos para formar sextinas u octavas, invitaba, sin duda, a la lectura pública: Gli animali parlanti, a modo de apólogos de zooépica burlesca, pero, sobre todo, las

\footnotetext{
${ }^{2}$ El texto de El Encantamiento se encuentra en el segundo tomo (Ms. 4083-4084), ff. 201r.-207r..

${ }^{3}$ Un estudio sobre las características del manuscrito español se encuentra en ARCE 2007. Para el texto de la carta de Pascual Asensio a Hartzenbusch, entonces director de la Nacional, con datos muy interesantes sobre la traducción, ver, especialmente, las pp. 491-493 del citado trabajo.

${ }^{4}$ Para datos biobibliográficos sobre el autor (1721?-1803) remito a la entrada correspondiente del DBI (NIGRO 1979). Para una posible rectificación de su fecha de nacimiento, de 1724 a 1721, ver ARCE 2000.

${ }^{5}$ Ya sexagenario comenzó su carrera literaria, dentro de la poesía narrativa: Il poema tartaro -doce cantos alegóricos en octavas contra Catalina II y la depravada corte de la zarina en San Petersburgo (Milán 1796, aunque terminado 13 años antes)- o Gli animali parlanti (París 1801-02), poema en sextinas contra la Francia contemporánea surgida de la revolución y cuya sátira zoomorfa influyó en la obra de Goya, que le hizo un retrato. Escribió también poesías jocosas, un amplio Epistolario con interesantes noticias y varios libretos de melodramas para la corte vienesa (década de 1780).

${ }^{6}$ En el Index librorum prohibitorum 1800-1808 (decreto de 2 de julio de 1804), se incluye «l'opera intitolata Novelle amene [sic] del cittadino Casti» (Index: 130), junto con obras de Voltaire y de La Fontaine, entre otros. La misma suerte corrió el poema Gli animali parlanti, condenado el 26 de agosto de 1805 (decreto del Index 1800-1808). Pormenores sobre los problemas de Casti con la censura pueden verse en ARCE 2007.
} 
Novelle galanti ${ }^{7}$, auténticos cuentos de variada extensión cuyos argumentos 'subidos de tono' o que rozaban lo blasfemo e irreverente, podían no ser, en principio, los más apropiados para ser escuchados en voz alta por los 'castos' oídos de unas damas que escondían sus risitas nerviosas en cualquier tertulia tras el abanico, ante una taza de humeante chocolate.

He hablado del éxito y de los problemas editoriales que acompañaron la obra impresa de Casti, que trascendió las fronteras de Italia; las varias traducciones castellanas confirman la fama de la que gozó en nuestro país, que visitó hacia 1781, si bien la 'clandestinidad' en la que se mueven explican el carácter generalmente anónimo, inédito o incompleto de las traducciones y que éstas fueran obra de liberales en el exilio tanto laicos como eclesiásticos. No es el momento de hablar de las distintas versiones en español de las 'otras' obras castianas $^{8}$, pero en lo que respecta a las Novelle galanti, escritas entre 1766 y 1802, puede decirse que tuvieron, al menos, tres traducciones incompletas en castellano en un puritano siglo XIX ${ }^{9}$, aunque de fecha imprecisa. De las tres, de muy distinta calidad pero generalmente fieles al contenido, me voy a fijar en este momento en la anónima y manuscrita que se conserva en la Biblioteca Nacional de Madrid (ARCE 2007), cuyo traductor, posiblemente cercano al círculo hispanoitaliano de exiliados que coincidían en las reuniones que se celebraban en casa del embajador Nicolás de Azara en París, hace una versión cuidada y literal de la obra de Casti, aunque limitada a cuarenta y tres de los cuarenta y ocho cuentos que forman la colección definitiva de las Novelle en la que se mezclan variados y sugerentes argumentos basados en temáticas originales o en la cuentística tradicional ${ }^{10}$.

El cuento titulado L'Incantesimo, que voy a estudiar a continuación y cuyo texto inédito en castellano se publica en Apéndice como El Encantamiento, es uno de los siete que el abate ilustrado toma de Boccaccio ${ }^{11}$. Ubicado con el número XLIV en la edición parisina de las Novelle al inicio del nuevo siglo (CASTI 1801), reproduce con ligeras va-

${ }^{7}$ A causa de las ediciones apócrifas que el autor no podía siempre controlar, la obra fue publicada también como Novelle, como Novelle licenziose o Novelle amene, título con el que se cita en el Index de 1804 y que se mantiene, por ejemplo, en la entrada «Casti, Giovanni Battista» de la Enciclopedia cattolica (Città del Vaticano, 1949: 1032-33).

${ }^{8}$ Conozco la existencia de una edición bilingüe anónima del libreto del Rey Teodoro en Venecia (Madrid, Imprenta de Benito Cano, 1788) y de cinco -parciales, completas, en verso, en prosa ...- de Gli animali parlanti. Sobre su papel como traductor remito a la voz «Casti, Giambattista» que he preparado para el DHTE (Diccionario Histórico de la Traducción en España).

${ }^{9}$ La única impresa (París, Rignoux, s.a.) se limitó al cuento aislado La papisa, traducción casi literal -si bien se presenta en la portada como «novela orijinal ... de un espatriado»- de la novella XXXII de Casti, dividida en tres partes por su extensión, así como de algunas de las notas históricas en prosa que la acompañan al final del texto versificado en octavas. La otra versión de 17 novelle -todas inéditas en el Museo Canario de Las Palmas y en el archivo privado de la familia Cambreleng, salvo Las bragas de San Grifón (Las Palmas, Cabildo de Gran Canaria, 2003) - se debe al «Doctoral de Canarias» Graciliano Afonso (1775-1861), que mantiene los títulos literales aunque adapta libremente el texto a silvas de heptasílabos y endecasílabos. Agradezco a don Diego Cambreleng las facilidades que me ha dado para acceder a su archivo.

${ }^{10}$ Junto a la originalidad de temáticas históricas o mitológicas (ARCE 2003), hay otros cuentos sacados de colecciones orientales o de novellieri tanto italianos (Boccaccio, Sacchetti, Masuccio Salernitano, Firenzuola o Bandello) como franceses (Grécourt, Voltaire o La Fontaine).

${ }^{11}$ Además de éste que nos ocupa, Casti tiene en cuenta al novelista medieval en los seis casos siguientes: novella V: La Celia (Decameron VIII, 4); VIII: Il Purgatorio (III, 8); XI: Il Rosignolo (V, 4) [ARCE 1999]; XXV: La Comunanza (VIII, 8); XXXVI: L'Arcangelo Gabriello (IV, 2) y, finalmente, el XL: Il Diavolo nell'Inferno (III, 10). De los siete cuentos basados en Boccaccio, la versión española no incluye, o se ha perdido, únicamente la novella XXXVI, que sí se traduce, en cambio, entre las del canario Afonso. Seguiré para las citas del Decameron, la ya clásica edición, y todavía insustituible, de Vittore Branca (BocCACCıO 1992) con sus útiles párrafos (§). 
riantes -salvo tres versos de la oct. 27 que comentaré oportunamente más adelante- ${ }^{12}$ un texto escrito con anterioridad, ya que el público lo conocía entre las primeras diez y ocho novelitas publicadas por el abate (CASTI 1797). Con sus treinta y ocho octavas nos encontramos ante una de las narraciones más breves de la colección italiana en la que se versifica puntualmente la prosa del último cuento de la novena Jornada del Decameron ${ }^{13}$, sin reproducir las variantes introducidas por La Fontaine, como intermediario de la fuente boccaccesca ${ }^{14}$, cambios tampoco tenidos en cuenta, como es obvio, por el español que seguirá únicamente el texto italiano del XVIII que quiere traducir.

El argumento, del que se encuentran antecedentes en el folklore tradicional de épocas diferentes ${ }^{15}$, se desarrolla en la paupérrima campiña del Sur de Italia, país que el traductor no quiere identificar, donde una humilde pareja de campesinos acoge en su casa a un párroco con escasos recursos económicos, motivo por el cual estará obligado a frecuentar los mercados donde había coincidido, en repetidas ocasiones, con el marido. Como agradecimiento para con sus anfitriones y para mejorar la precaria situación económica que también éstos padecían, les sugiere una solución 'mágica' que, según les confiesa, él solía practicar a diario: el 'original' ofrecimiento consiste en que, haciendo las veces de mago, transformará a la mujer en yegua durante el día, con el objeto de que ayudara a su marido en el transporte de mercancías, mientras que, por la noche, ésta recuperaría de nuevo su estado humano, para poder cumplir con sus obligaciones de esposa. La picardía del relato se incrementa con las insistentes advertencias del párroco al ingenuo y confiado marido ya que, para que el hechizo pudiera concluirse con éxito, el esposo debería estar presente durante la problemática metamorfosis -con el objeto de que después pudiera repetirla sin su ayuda- aunque, a cambio, no podrá intervenir en ningún momento, ni tan siquiera, cuando el 'mago' tenga que «aplicar la cola» al animal, momento crítico y fundamental del difícil hechizo.

Son tres los protagonistas principales del cuento dieciochesco ${ }^{16}$ : por un lado nos presenta a un ingenuo matrimonio -caldo de cultivo perfecto para creer en supersticiones por su incultura y por el primitivismo social en el que vive ${ }^{17}$-, pareja formada por un marido crédulo o excesivamente confiado y una joven y bella esposa insatisfecha, y por otro, tenemos a un ecle-

${ }^{12}$ Las variantes afectan a signos de puntuación, uso de mayúsculas, a formas verbales del tipo furon/fur (oct. 2), comprar/comperar (3), prega/pregò (14), vuò/vo' (25), etc., o más significativas, aunque mínimas, como trasmutate/trasformate (21).

${ }^{13}$ El cuento está narrado por Dioneo en la Jornada de tema libre regida por Emilia: Donno Gianni ad istanza di compar Pietro fa lo 'ncantesimo per far diventar la moglie una cavalla; e quando viene ad appicar la coda, compar Pietro, dicendo che non vi voleva coda, guasta tutto lo 'ncantamento (Decameron, IX, 10). La brevedad también la menciona Dioneo en el cuento medieval: «Dirovvi adunque una novella non troppo lunga» (BocCACCIO 1992, § 5).

${ }^{14}$ En efecto, será ésta una de las veinte narraciones que el fabulista francés seguirá de Boccaccio en sus $C$ ontes et nouvelles en vers (1674) bajo el título de La jument du compère Pierre, incluidos en el Index romano a partir de 1703 (LA FONTAINE 2002).

${ }^{15}$ Se cree que Boccaccio tuvo presente un anónimo fabliau en octosílabos, titulado De la pucelle qui vouloit voler, otras veces atribuido a Rutebeuf (primera mitad del s. XIII), sin descartar que el tema de las metamorfosis de hombres en animales ya aparecía en el Talmud, la Biblia, la Patrística, en la mitología, Ovidio y Apuleyo. Más tarde, aparecerá también en San Agustín y en leyendas agiográficas que Boccaccio parodia (GuTHMÜLLER 2002).

${ }^{16}$ A pesar de estar siguiendo a Boccaccio, los tres personajes son figuras recurrentes de las novelle del abate. Se menciona, además de éstos, a una vecina, la comare Pepparella Bellavita (oct. 11), que pasa a «la Rita / su comadre y amiga de la infancia» (11), que no va a influir en el desarrollo de la trama.

${ }^{17}$ Marco que contrasta con el ambiente culto e ilustrado que Casti solía frecuentar. 
siástico lascivo que, respetado por ellos por la 'honorabilidad' que representa su magisterio ${ }^{18}$, sabrá sacar partido de una situación que él no ha propiciado, lo que resalta la comicidad, o yo más bien diría el dramatismo, de la embarazosa situación que vamos a presenciar ${ }^{19}$.

Siguiendo un modelo de la más pura narratividad, en el que ni siquiera faltan dos octavas a modo de introducción del relato, las treinta y seis estancias restantes pueden distribuirse en tres partes claramente diferenciadas: A) presentación de los protagonistas y ubicación de la historia, previo todo al encantamiento (octs. 3-16); B) desarrollo del hechizo con toda la parafernalia mágica que implica el complicado ritual (octs. 17-26) y C) desenlace de los acontecimientos después del fallido sortilegio (octs. 27-38) que tendrá consecuencias diferentes para cada uno de los implicados.

El traductor, respetuoso con la ubicación y el título de los cuentos así como con el número de octavas, es fiel al esquema del cuento original demostrando, en general, un profundo dominio de la lengua italiana, lo cual no es óbice para que, a veces, caiga en algunos errores debidos no siempre a simples erratas de interpretación -mínimas en relación al volumen de lo traducido- sino a exigencias de la férrea métrica de la octava o a la lógica adaptación entre dos lenguas tan afines ${ }^{20}$.

El primer problema con el que se enfrenta nuestro anónimo traductor es con el nombre de los protagonistas. Casti, preciso en la elección de su léxico, había modificado a Boccaccio - compar Pietro y comar Gemmata ( $\$ 7$ y 11)-, con formas más cómicas y populares como compar Checco y monna Zita Caramella ${ }^{21}$. El traductor opta por la literalidad e igual número de sílabas y nos los presenta como «compadre Checo» y «Cita Caramuda» (oct. 7 y 8) sin parecer darse cuenta de que la pronunciación palatal española del primer nombre sustituía la gutural italiana y no sabiendo cómo traducir las formas dialectales de monna y zita. El nombre del eclesiástico, sin embargo, se traduce sin mayor problema: Don Gianni $\rightarrow$ «Don Juan» ${ }^{22}$ al que se refiere una vez con un irónico «dicemisa» (oct. 37) y en veinte ocasiones con un genérico «el Cura» ${ }^{23}$.

\footnotetext{
${ }^{18}$ A pesar de que el cura también es pobre, su status social es superior al de la extrema miseria de sus anfitriones, motivo por el cual ellos lo agasajan.

${ }^{19}$ En efecto, el 'embaucador' no se nos presenta como instigador del engaño, sino que parece, más bien, que ha sido inducido y hasta obligado por el matrimonio para llevar a cabo el sortilegio. Y aunque en todo momento se habla de la incultura de los dos miembros de la pareja, será la esposa -como la bíblica Eva- la primera en ser engañada al escuchar y creer ciegamente las palabras del cura, y por eso, intentará con vehemencia convencer a su marido de lo útil que ella le sería una vez transformada en animal de carga.

${ }^{20}$ Véase como ejemplo de pequeña errata la ubicada en la oct. 2, después de que en la primera la dedicatoria a las donne mie pasara al también bisílabo «niñas mías». En el v. 2, «Fueron del crédulo y ciego gentilísimo», después de un calco perfecto de los dos adjetivos, credulo e cieco, traduce como «gentilísimo», en vez de 'gentilismo', el gentilesimo italiano, sinónimo de 'paganismo o religión de los gentiles', fallo o despiste más incomprensible aún, si vemos la rima obligada de los vv. 4 y 6, «cristianismo» y «magicismo». Capta, en cambio, el significado de becco como «cabrón», la bella moglie, lui converse in becco (v. 8), si bien se aumenta el tono irónico al cambiar la ubicación de un mismo adjetivo: la bella moglie $\rightarrow$ «un cabrón muy bello». Para el texto italiano utilizo la edición parisina del Anno IX (CASTI 1801-02), primera de las 48 novelle.

${ }^{21}$ La primera vez que aparece el nombre del marido (oct. 2, v. 7) Casti lo hace rimar con becco es decir, «caprone, marito ingannato dalla moglie, cornuto» (GDLI), de igual manera, Zita Caramella aúna la forma dialectal meridional zita, «ragazza, giovane sposa» (GDLI) -también utilizada en Apulia como nombre propio-, con la de 'golosina dulce y apetecible'.

${ }^{22}$ Es el único nombre que se mantiene en las respectivas lenguas, ya que el también donno Gianni de Boccaccio pasa a Messire Jean en la versión de La Fontaine.

${ }^{23}$ Se habla del «Cura» en las octs. 2, 3, 4, 5, 6, 9, 10, 11, 13, 15, 25, 27, 29, 32, 34, 35, 36 y 38, cuando el texto italiano, más rico en su léxico, alterna con parroco (oct. 3 ), curato (10), prete (4 y 5), con un pronombre (11
} 
En lo referente a la localización geográfica de la historia, el traductor va a tratar de desvincularla del ambiente italiano. Casti la había situado, como su modelo medieval, en una región del sur de Italia, precisándolo con algunos nombres reales: Barletta (3 y 10), Puglia (7) y castel Tresanti (8 y10) ${ }^{24}$, que pasan a «Barleta» (3) y «Tres Santos» (8), sin precisar en ningún momento su localización ni hacer referencia a la región italiana. Lo mismo va a suceder con la 'hispanización' de unas monedas que aparecen en la octava tercera referentes a la remuneración económica del eclesiástico ${ }^{25}$. Esta adaptación monetaria del traductor me sirve para introducir una digresión que, como buen ilustrado crítico y polemista, Casti hace contra la Iglesia a propósito de la actividad mercantil de don Gianni y de la precaria situación económica de la parroquia que regentaba ${ }^{26}$. Nada menos que tres octavas (4-6), en una narración tan breve, se dedican a la condena moral del trabajo que tiene que ejercer el párroco para su supervivencia, comercio del que la Curia es la única culpable ${ }^{27}$. No se escatiman duras palabras por parte del abate dieciochesco pero, si cabe, el traductor español pone de manifiesto su mayor anticlericalismo ante aquellos que «dormitando entre el placer y el ocio / se revuelcan cual cerdos entre el vicio» (oct. 5 , vv. 5-6) que no aparecía en el original, así como cierto tono ético de «ni yo pretendo ser censor severo» (oct. 6).

Con un típico 'volvamos a nuestra historia', para salir de la digresión apenas comentada, en la oct. 7 comienza el relato propiamente dicho con la descripción del matrimonio: él, un «hombre contrahecho y seco», ella «joven y no fea» ${ }^{28}$ y ambos de escasa inteligencia ya que «eran dos burros en figura humana» (8) aptos para creer y aceptar lo que se les avecinaba. Del cura no se dice nada en este momento, ya que se reservará para más adelante la explicación de su cínica actitud y su deseo libidinoso de fogoso semental, para preservar, quizás, la primera parte del cuento de todo matiz erótico. En efecto, se habla de la amistad que en todo momento reinaba en el ambiente (oct. 9) y de la casa de los anfitriones, extremadamente humilde pero llena de generosa hospitalidad, re-

y 13) o el nombre propio don Gianni (octs. 2, 27, 29 y 35) y diez veces con piovano $(6,9,11,15,25,32,34,35$, 36 y 38 ) o pievano, es decir como «prete che regge una pieve» (GDLI) o parroquia.

${ }^{24}$ Tanto Barletta como Tresanti, más al norte, son localidades de la región de Apulia.

${ }^{25}$ En efecto, los trenta giuli (oct. 3, v. 2) mensuales que don Gianni recibe como párroco y que le obligarán a ejercer un trabajo extra para sobrevivir y obtener qualche tornese (v. 4), se convierten en los «tres duros por mes» para «ganar algo» (vv. 2 y 4) que don Juan necesita para su supervivencia. Tanto el giulio como el tornese, moneda de valor inferior, son nombres identificables en numismática y de uso legal, respectivamente, en los Estados Pontificios y en el Reino de Nápoles a partir del siglo XVI.

${ }^{26}$ Boccaccio, sin más pormenores, se había limitado a decir que «donno Gianni» trabajaba porque «povera chiesa avea» (BOCCACCIO 1992: $§ 6$ ).

${ }^{27}$ Los productos del 'mercadeo' de los dos últimos endecasílabos de la oct. 3 varían en el español sin justificación aparente, como no fuera por la métrica:

$\begin{array}{lll}\begin{array}{ll}\text { legumi } \\ \text { fichi secchi }\end{array} & \rightarrow & \begin{array}{l}\text { higos secos } \\ \text { pasas } \\ \text { piñones }\end{array} \\ \text { cipolle } & \rightarrow & \text { cevollas } \\ \text { agli } & & \end{array}$

salumi

${ }^{28}$ Sustituyendo con una formulación negativa - «no fea»- la adjetivación positiva del original: giovin ben tarchiata e bella traducible como una 'joven bien maciza y hermosa'. 
forzada por la afectividad de los cuatro diminutivos de la oct. 10, de los que el español sólo reproduce uno ${ }^{29}$.

En este ambiente de emotiva familiaridad, el astuto párroco comienza a urdir con disimulo su engaño: Cita le insiste «de continuo» y le ofrece su lecho en vez del incómodo lugar que él tiene asignado en el establo (11), pero don Juan rechaza el ofrecimiento con una sorprendente confesión que deja atónita a la mujer ${ }^{30}$. La astucia del cura contrasta con la ingenuidad de ella que, no sospechando de que pueda ser víctima de un engaño, le propone a su marido la posibilidad de ser transformada «pues ganarás el doble y te harás rico / conmigo vuelta en yegua y el borrico» (13). Entusiasmado Checo - «cuya idiotez no tiene tasa»- con la propuesta, busca a don Juan «y le pide por Dios santo / que a hacer le enseñe su precioso encanto» (14). Nadie podría decir que estamos ante un aprovechado timador -aunque éste se ría a escondidas imaginando el beneficio que va a conseguir- ya que el párroco rechaza por segunda vez la petición de sus 'víctimas' y sólo accede a llevar a cabo lo que considera una «locura», «pues tu empeño veo» (15) y por «la amistad que nos tenemos» ${ }^{31}$, imponiendo sólo una condición que, para que nadie después se venga a engaños, no será nada fácil: «Mas devo hacerte una advertencia sola: / que el gran misterio es aplicar la cola» $(16)^{32}$.

Con la llegada del nuevo día para el impaciente matrimonio, se pasa a la segunda parte de la historia (octs. 17-26) consistente en el desarrollo, paso a paso, del 'encantamiento' que da título al relato. Una vez más, ¡y es la tercera!, don Juan se muestra reticente sobre la conveniencia o no de llevar a cabo la metamorfosis, pero consciente de que tiene que cumplir su palabra, «con la voz severa»-expresión que da mayor sensación de solemnidad que no aparecía en el italiano- el 'mago' impone nuevas condiciones para que el sortilegio surta el efecto deseado: el esposo, con un candil en la mano para iluminar la escena (18), observará atentamente todo el proceso -para poder después repetirlo sin la ayuda del 'maestro de ceremonias'-, aunque en ningún momento podrá intervenir si lo que quiere es «que el encanto se consiga» (19) ${ }^{33}$. Convencido Checo de que va a ser capaz de cumplir los exigentes requisitos, la escena se inicia con la obligada desnudez de la mujer, imprescindible para la transformación de una naturaleza -la humana-, a otra, la equina $^{34}$. Si en el evidente equívoco de justificar como natural una actitud claramente des-

\footnotetext{
${ }^{29}$ De los cuatro, el traductor sólo reproduce el segundo: cameretta $\rightarrow$ «cuarto»; stalletta $\rightarrow$ «cuadrita»; somarel $\rightarrow$ «burro» y letticello $\rightarrow$ con un cortante «mal camastro». También desaparece la adjetivación positiva: bella moglie (v. 3) y buon curato di Barletta (v. 5) que pasan simplemente a «su muger» y «el cura» sin especificación geográfica de procedencia.

${ }^{30}$ Octava 12: «Déjame en esta cuadra, Cita bella / Y que aquí siga de mi encanto usando / Por el cual mudo en muy linda doncella / A mi yegua en el punto que lo mando / Durmiendo y solazándome con ella, / Hasta que veo que se acerca el día / Y a la forma la vuelvo que tenía».

${ }^{31}$ En italiano el efecto era más impactante a causa de una retórica imprecación: il ciel mi faccia gramo (16), es decir, ' el cielo me haga vil, miserable'.

${ }^{32}$ Son varias las ocasiones en las que en el texto se repite el sintagma «aplicar la cola» aunque con pequeñas variantes (octs. 16, 19, 23, 25, 29, 30, 32, 35, 36 y 38).

${ }^{33}$ Se sustituye de nuevo con una forma positiva la negativa expresada por Casti: Ché se tu aliti sol, l'incanto è rotto (oct. 19).

${ }^{34}$ El desnudo femenino, unido al tocamiento exigido por el propio ritual, será el que va a desencadenar en el lúbrico párroco el 'despertar de sus bajos instintos', planteándolo como el resultado de un mero acto natural y previsible de la propia naturaleza masculina y no como un hecho obsceno provocado simplemente por la malicia del momento.
} 
honesta Casti había seguido las huellas de Boccaccio (GUTHMÜLLER 2002), se va a distanciar, en cambio, de la fuente medieval en la descripción de la compleja parafernalia del propio encantamiento que va a ocupar las dos octavas siguientes. Con la mujer desnuda ${ }^{35}$ en medio de la humilde habitación -advertida de que como su 'vigilante' marido deberá guardar absoluto silencio, sienta lo que sienta (vv. 4 y 6)-, y puesta en cuadrupedia para facilitar la metamorfosis, se inicia la ceremonia en la que el improvisado mago dará tres vueltas en torno a ella (oct. 20):

Y luego hace que Cita en cueros puesta Y en cuatro pies, cual si una burra fuese, Oiga lo que $1 a^{36}$ dice y amonesta, Y es: que por más que vea o que sintiese Se guarde de decir mi boca es ésta, Y hacer le deje aunque haga lo que hiciese. Da en derredor tres vueltas, y entretanto Con estas voces pincipió el encanto:
E comar Zita poi fe' dispogliare

E nuda nata a guisa di giumenta, Co'i piedi e mani a terra la fe' stare, E poscia l'avvertisce e le rammenta, Che non faccia parola, e lasci fare Qualunque operazione o veda o senta; Poi le girò tre volte intorno, e intanto Con tai parole incominciò l'incanto:

mientras don Gianni/don Juan invoca, en un mágico ritual, a divinidades del mundo pagano, junto a otros personajes bíblicos relacionados, siempre, con distintas metamorfosis animales (oct. 21):

«Vosotros ;o Astaroht, Nesroch ${ }^{37}$, Beliam! Dadme atención, y que mi voz os mueva. Yo os conjuro por la alma de Abraham A vosotros, que hicisteis la gran prueva De que hablase la burra de Balaam ${ }^{39}$ $\mathrm{Y}$ a Navuco de buey dar forma nueva ${ }^{40}$.
«Voi Baalim ed Astaroth ${ }^{38}$ io chiamo, Che i corpi trasformate in forme nuove, Voi scongiuro per l'anima d'Abramo, Voi che faceste le stupende prove Di far parlar l'asin di Balamo, E Nabucdonosor cangiaste in bove,

${ }^{35}$ El coloquial «en cueros» reproduce también una fórmula popular, nuda nata, equivalente a 'como Dios la trajo al mundo' (oct. 20).

${ }^{36} \mathrm{El}$ anónimo traductor español es laísta, uno de los rasgos lingüísticos que lo caracterizan, aunque no nos sirva totalmente para ubicar su procedencia. Además de éste, se encuentran más ejemplos de laísmo, y varios en una misma estancia, en las octs. $12,22,35$ y 36.

${ }^{37} \mathrm{El}$ traductor añade a los dos invocados por el italiano (v. 1) este otro nombre de dios pagano, que aparece con grafía diferente según las fuentes como Nesroc o Nisroch, al parecer, forma contaminada por Marduk, importante divinidad de Babilonia. Su nombre aparece también en la Biblia (Libro de los Reyes 19, 35-37 y en Isaías 37, 36-38).

${ }^{38}$ Casti hace referencia a una 'pareja' de dioses fenicios que se relacionaron después con los semitas: las distintas advocaciones de Baal lo consideran como la divinidad principal del panteón cananeo encargado de la fertilidad de la tierra, mientras que la diosa Astarté, que los griegos asimilaron a Afrodita, representaba la fertilidad de la naturaleza, ya que en sus santuarios se practicaba la prostitución ritual. La oscilante grafía de los nombres hace que en ediciones anteriores (CASTI 1797) aparecieran como Banlahim ed Asteroth así como el Nabuconosor del v. 6.

${ }^{39}$ Éste es el primero de los dos episodios bíblicos a los que, como ejemplos, se hace alusión en el texto; se menciona la leyenda de la burra del profeta y adivino Balaam (siglo XIII a.C.), animal que gozó temporalmente del don de la palabra para incitar a su amo a obedecer a Yahvé y bendecir a los hebreos, en vez de al rey Moab, que pretendía expulsarlos de su territorio.

${ }^{40}$ Se recuerda el sueño de Nabucodonosor II, rey de Babilonia (siglo VI a.C.) «Navuco» en el español por evidentes motivos métricos-, a quien se le profetizó que comería hierba como un buey durante siete años, según la interpretación del profeta Daniel. Casti podría tener presente en esta ocasión a Voltaire que en La Bible enfin expliquée (1776) reprodujo en tono jocoso el episodio de Nabucodonosor convertido en buey. 
¡Espíritus de figura y sexo informe $e^{41}$

Haced que Cita en yegua se transforme!».
Spirti di sesso e natura difformi, Per voi Zita in cavalla si trasformi».

Junto con las palabras rituales, el sentido del tacto cobrará un protagonismo especial en las dos octavas que siguen (22 y 23), ya que, según lo previsto y después del iniciático conjuro, vamos a asistir al intento de una transformación del cuerpo de la mujer parte por parte ${ }^{42}$. En una sola octava, la 22, se condensa, como si se tratase de un juego infantil, todo el ritual mágico, con la repetición en cuatro ocasiones de la forma verbal toccare -que pasan a tres en la traducción- acompañada de la parte corporal correspondiente en vías de transformación ${ }^{43}$ :

Tócala ${ }^{44}$ luego la caveza y rostro, y dice ${ }^{45}$ : «Sea esta caveza y rostro de una yegua». Toca lomos y piernas luego, y dice: «Sean estas piernas y lomo de una yegua». Después tocóla el pecho y la barriga, y dice: «Sea este pecho y barriga de una yegua». Y así las demás partes recorriendo Iba la misma frase repitiendo.
Allor toccolle e faccia e testa, e disse: «Questo sia muso e testa di cavalla»; Indi toccolle e braccia e schiena, e disse: «Queste sien gambe e schiena di cavalla», Poscia toccolle e petto e pancia, e disse: «Questo sia petto e pancia di cavalla»: E toccando ogni parte tuttavia La stessa frase replicando gìa.

La intención de Casti en esta octava es clara, así como su precisión léxica, como se observa en la mezcla de nomenclatura humana y animal con el claro propósito de que la progresiva metamorfosis estuviera presente en la mente de todos; después de la minuciosidad descriptiva de los primeros versos con la mención explícita de seis zonas corporales $^{46}$, la alusión genérica a la ogni parte restante -las «demás partes» del penúltimo endecasílabo-, podría hacernos intuir que el desenlace del encantamiento estaba felizmente llegando a su fin, sin más explicaciones. Sin embargo, lo más comprometido estaba aún por llegar.

${ }^{41} \mathrm{El}$ traductor modifica el difformi, es decir, de 'diferente' naturaleza, por «informe», 'que no tiene la forma que le corresponde', con ligero matiz semántico diferente.

${ }^{42}$ La indudable comicidad de una situación altamente comprometida no está exenta, sin embargo, de cierta amargura ya que, en el fondo, nos encontramos ante la intimidad de un pobre e ingenuo matrimonio que será violentamente profanada por el engaño de alguien sin escrúpulos, en quien confían ciegamente y contra el que ellos no pueden defenderse porque lo consideran superior.

${ }^{43}$ Es éste uno de los más claros ejemplos en el que Casti parafrasea a Boccaccio: «E con le mani cominciandole a toccare il viso e la testa cominciò a dire: 'Questa sia bella testa di cavalla'; e toccandole i capelli disse: 'Questi sieno belli crini di cavalla'; e poi toccandole le braccia disse: 'E queste sieno belle gambe e belli piedi di cavalla'» (BoCCACCIO 1992, § 17-18).

${ }^{44}$ Siguen en esta octava más casos de laísmo.

${ }^{45}$ El cambio del pasado disse al presente histórico «dice» suaviza eufónicamente un ‘dijo' que tendría que repetirse tres veces por exigencias métricas de la octava.

${ }^{46}$ Véase en el siguiente esquema como el léxico del italiano es más preciso que el del anónimo traductor que suele repetir los términos, aunque fuera a base de 'humanizar' lo animal, sin que en este caso la rima o la medida del verso le obligaran a hacerlo:

faccia - testa $\rightarrow$ rostro - caveza

muso - testa $\rightarrow$ rostro (en vez del trisílabo 'hocico') - caveza

braccia - schiena $\rightarrow$ piernas (en vez de traducir 'brazos') - lomos (en vez de 'espalda')

gambe - schiena $\rightarrow$ piernas - lomo (ambos correctos para el animal, como los términos italianos)

petto - pancia $\rightarrow$ pecho - barriga

petto - pancia $\rightarrow$ pecho - barriga 
En la octava 23, el tono erótico de la escena 'sube' todavía un poco más, al describirnos el resultado fisiológico del impulso 'natural' del excitado párroco. Si Casti no había tenido inconveniente en 'elevar' su lenguaje, intercalando magistralmente lo explícito y lo metafórico, la versión castellana, si cabe, es mucho más directa (oct. 23):

El viril miembro en esta bataola ${ }^{47}$

$\mathrm{Y}$ con tanto lascivo tocamiento

Se engríe, se endurece, y se enarbola;

Y no faltando ya al encantamiento

Sino tan sólo el aplicar la cola,

Se alza de la camisa el faldamento,

El dardo envayna, y dice sin más tregua:

«Que sea esto, pues, la cola de la yegua».
Ma in palpeggiar la ciccia fresca e soda

Di fervido desir s'accese, e intanto

Drizza la testa, se gl'ingrossa e assoda

Il piantator degli uomini, e all'incanto

Più non mancando che appiccar la coda,

Alzata a un tratto la camicia alquanto

Entro il solco il piuol pianta e non falla,

Con dir: «questa sia coda di cavalla».

Nuestro anónimo habla con claridad meridiana de cómo el «viril miembro» se 'ha ido modificando' a causa de «tanto lascivo tocamiento», utilizando las tres acciones verbales del verso tercero que se explican por sí solas ${ }^{48}$. Casti había parafraseado a Boccaccio, como lo había hecho en la estrofa anterior ${ }^{49}$, utilizando un mismo adjetivo -sodo ${ }^{50}$ - y los elementos metafóricos que pretendían 'suavizar' descripciones comprometidas, si bien añadiendo de su propia cosecha un sintagma tan táctil y sugerente como palpeggiar la ciccia -es decir, 'palpar repetidamente la carne humana'-y algunas explicaciones referidas a la anatomía masculina que, evidentemente, no eran necesarias. La metáfora de tipo agrícola que estaba presente de manera similar en los dos autores italianos -piantator degli uomini, piuol o el solco de la tierra donde la estaca será inserta$\mathrm{da}^{51}$ - desaparece en la traducción, que prefiere una indicación más directa como la de «el dardo envayna» para identificarlo con el apéndice equino, último elemento del hechizo que aún quedaba para la metamorfosis definitiva ${ }^{52}$.

En este punto del cuento, donde la tensión era extrema, Casti demuestra su valía como narrador ingenioso. Recordemos de nuevo que sus novelle, con mayor o menor car-

\footnotetext{
${ }^{47}$ No deja de ser significativo que el traductor utilice el término batahola, derivado del italiano battagliola, diminutivo de battaglia. En el Dicc. Aut. Se dice que es «voz jocosa».

${ }^{48}$ Tampoco el italiano se quedaba corto con los tres verbos que utiliza: drizzare, 'ponerse en posición vertical, ingrossare, 'engrosar', y assodare, 'llenarse de vigor' (v. 3).

${ }^{49}$ Se decía en el Decameron: «Poi toccandole il petto e trovandolo sodo e tondo, risvegliandosi tale che non era chiamato e sú levandosi, disse [...] e ultimamente [...] levata la camiscia e preso il pivuolo col quale egli piantava gli uomini e prestamente nel solco per ciò fatto messolo, disse: 'E questa sia bella coda di cavalla'» (BoCCACCIO 1992: § 18).

${ }^{50}$ Casti no duda en 'reutilizar' el adjetivo, ya que la definición del GDLI le encaja a la perfección: «Sodo: Che presenta compattezza e tonicità muscolare; che si avverte compatto e ben rilevato allo sguardo o al tatto (il corpo, una sua parte)».

${ }^{51}$ Cualquiera de los términos utilizados tanto por Boccaccio como por Casti, suelen tener doble sentido: Piantatore $=$ quien se dedica a todo tipo de labores agrícolas, y, por tanto, «che da vita, che crea»; también «membro virile con valore scherzoso» (GDLI). Piuol = de piolo o el pivuolo de Boccaccio, es decir, «estaca» cilíndrica de medidas determinadas muy 'sugerentes' que se clava en la tierra, pero también «con allusione oscena: il pene» (GDLI). Solco = hendidura hecha en la tierra para la siembra, pero también «penetrazione sessuale» (GDLI).

${ }^{52}$ Para que entendamos realmente la situación, me parece oportuno que no olvidemos que esta singular escena tiene lugar delante del marido quien, hasta ese momento, había cumplido su parte del trato observando el espectáculo protagonizado por el cura y su esposa en el más absoluto silencio e inmovilidad.
} 
ga erótica, iban dirigidas a un público femenino, a unas mujeres que no sólo podían leerlas en la intimidad de sus aposentos privados, sino que debían 'escucharlas', con la lectura en voz alta del propio autor, en tertulias o reuniones sociales. Y en ese ambiente, que podemos suponer tenso con las risitas más o menos nerviosas de unas damas presumiblemente ruborizadas ante una trama que podría considerarse obscena, el autor demuestra gran dominio de la situación, como si de un director de escena se tratase, e intenta relajar la tirantez con la sensibilidad de un poeta, por lo que no duda en intercalar, a modo de respiro, dos octavas casi consecutivas (la $24^{53}$ y la 26) con sendos símiles poéticos. Hay que reconocer, sin embargo, que sobre todo el texto de la primera, no se aleja demasiado del erotismo del momento. En efecto, en el primer caso, el lascivo párroco es comparado con un fogoso semental -stallon foioso (v. 4)- que se aferra sbuffando nel furor lussurioso (v. 6) al lomo de su yegua, eso sí, en una idílica campagna amena con verdi prati (v. 2) ${ }^{54}$, mientras una villanella-obsérvese el poético diminutivo reproducido en «la aldeanilla» del español (v. 7) - presencia la escena escondiendo su excitación dietro al macchion desde donde «muerde el lavio y atisva enardecida» $(24, \text { v. } 8)^{55}$.

La carga erótica desaparece en el símil siguiente, separado del anterior por una octava también intensa (25), como se verá a continuación. La comparación, en este caso (26), es con un niño -denominado de nuevo con el diminutivo bambolin (v.1)- que «se enfurece, patea, llora y grita» (v. 5) cuando le arrebatan la golosina que consideraba suya y no estaba dispuesto a perder ${ }^{56}$.

Es precisamente ante la 'golosina' que, volviendo al hilo de la narración, el párroco tiene en ese momento entre manos, lo que hace que el hasta entonces impasible marido reaccione bruscamente gritando con determinación al final de la estrofa: 'io non vo' coda, io non vo' coda' (v. 8), como si empezara a percatarse del engaño del que ellos estaban siendo objeto y que hace decir al español con más precisión y «en tono fiero / 'yo no quiero esa cola, no la quiero'» (vv. 7-8). Y así, aproximándose hacia la esperpéntica escena y aún a riesgo de que «vaya el encanto a deshacerse» (v. 6), como añade el traductor por su cuenta, Checo intenta separar al fogoso atacante de su presa en la octava 25, situada en medio de las dos anteriormente comentadas ${ }^{57}$.

Sin embargo, a pesar de la prisa en actuar, posiblemente movido por los celos o por el desconcierto ante la 'violación' inesperada de su esposa, Checo no llega a tiempo para interrumpir el acto 'mágico', o yo más bien diría que llega en el momento justo para pre-

${ }^{53}$ Corregida la numeración en romanos, de XXVI a XXIV, como erróneamente aparece en la edición parisina del Año IX [1801-1802], cuyo texto sigo.

${ }^{54}$ De nuevo el traductor evitará hacer referencia a los nombres geográficos del original, Pisa, Coltano y Livorno, que ubicaban en Toscana la escena casi 'bucólica'.

${ }^{55}$ En el corpus de la RAE (CORDE) la voz atisvar recoge un solo ejemplo de comienzos del siglo XIX. Se trata de Apuntamientos para la Historia Natural de los páxaros del Paragüay y Río de la Plata (1802-1805) del geógrafo e historiador Félix de Azara, hermano del embajador en París que posiblemente conocía o pudo, incluso, ser 'mecenas' de nuestro anónimo traductor.

${ }^{56}$ La pera o albicocca del original (26, v. 1) se convierte en «higo o pera» (v. 2), ya que las cinco sílabas de 'albaricoque' debieron parecerle demasiado largas para introducirlas en el endecasílabo.

${ }^{57}$ El texto italiano decía: «Ma Checco, che secondo il convenuto / Attento e fiso a ogni parola a ogni atto / Stat'era fino allor, poiché ha veduto / Quell'appicar di coda e ciò mal fatto / A lui parendo, omai più restar muto / O non seppe o non volle, e ruppe il patto; / E rivolto al piovan la lingua snoda / Gridando, 'io non vo' coda, io non vo' coda'» (oct. 25). 
senciar, más de cerca y sin posibilidad de equívocos, el efecto dell'opra al termine (oct. 27):

Checo deja la luz, y al Cura viene, A quien, para apartarle, el brazo tira; Mas éste sovre Cita se mantiene Y más se encorva , empuja, aprieta, estira, Hasta que el gran placer término tiene $\mathrm{Y}$ de la húmeda vayna lo retira El generante miembro, aún goteando El suco radical que estava echando ${ }^{58}$.
Posa il lume, e a don Gianni in fretta viene, E per staccarlo il tira per le braccia, Ma alla donna vie più stretto si tiene, Se le incurva su i reni, e i fianchi abbraccia, Finché dell'opra al termine perviene; Fuor del fodero allor lo stocco caccia Cruccioso, qual se alcun la sete ammorza A un fonte, e altri di là lo tragga a forza.

Por si el texto italiano no fuera lo suficientemente explícito, el traductor español sustituye un bien estructurado verso bimembre del original (v. 4) por cuatro acciones verbales - «se encorva, empuja, aprieta, estira»- que expresan secuencialmente con mayor realismo la agitada escena hasta su culminación (v. 4). Podríamos decir que, en este caso como en otros muchos, las 'fuentes' del cuento se van ampliando: Casti había hecho ya un pequeño guiño a Boccaccio y lo que en el medieval concluía con un acto sexual inacabado, en el texto settecentesco el coito llega a su término aunque de forma brusca, que es lo que irritará al párroco en la octava siguiente. Finalmente, en la versión castellana se menciona expresamente, sin tapujos, que todo culmina cuando el marido no es capaz de interrumpir nada «hasta que el gran placer término tiene» (27, v. 5).

Antes de seguir con la interpretación textual respecto a la evolución de la escena que está teniendo lugar en la humilde casa de Checo y Cita, me parece imprescindible comentar uno de los puntos más significativos que ofrece la traducción manuscrita y que podrían servir para aclarar cuál de las ediciones italianas manejó el anónimo traductor español a la hora de realizar su trabajo (ARCE 2007). Ese punto se corresponde precisamente con los tres últimos endecasílabos de esta octava, la 27, donde el traductor, que en general tiene presente las ediciones parisinas del Anno IX y Anno XII, es decir, de las 48 novelas, sigue claramente en esta ocasión la variante utilizada por el propio Casti en las primeras ediciones de las 18 (CASTI 1797), variante más cercana al texto medieval y a la explicación científica que se utilizaba en la época para referirse al coito ${ }^{59}$. Compárense nuevamente estos tres versos de la traducción con el original de 1797, diferente al texto de 1801 que, anteriormente, he señalado (vv. 6-8):

Y de la húmeda vayna lo retira

El generante miembro, aún goteando

El suco radical que estava echando
Dall'umida guaina allora caccia

Il venerando arnese generante

Di sugo radicale ancor stillante.

donde puede verse que el paralelismo es ahora más evidente en esta traducción prácticamente literal que conserva sintagmas, sustantivos, adverbios o formas verbales del original italiano.

\footnotetext{
${ }^{58}$ Los tres últimos versos de la versión española (vv. 6-8) que parecen alejarse, en este caso, un poco más de lo habitual del texto italiano paralelo que estoy reproduciendo, serán explicados a continuación.

${ }^{59}$ En el Decameron se decía de manera similar: «Era già l'umido radicale per lo quale tutte le piante s'appiccano, venuto» (BoCCACCIO 1992: § 20).
} 
La brusca interrupción del encantamiento, que no del acto sexual como en la versión boccaccesca $^{60}$, es utilizada por don Juan para confirmar con irritación lo que antes había anticipado a los esposos y justificar, así, que la metamorfosis ha fallado porque el marido no ha cumplido la premisa imprescindible de su no intervención, y eso, «por no callar otro momento» (v. 4). El tono de la 'regañina' va en aumento ya que será imposible repetir lo interrumpido ${ }^{61}$.

A pesar de que el sufrido y «cuitado» Checo $(28, v .1)$ trata de justificar una y otra vez su impulsiva interrupción, ya que sigue pensando que una persona equivocada (29) colocó el apéndice en un lugar no idóneo (32), tiene que soportar estoicamente tanto la reprimenda del párroco (28) y sus peregrinas explicaciones de que el final de la metamorfosis debía hacerla la misma persona que la había comenzado (29), como las quejas de su indignada esposa que «hecha una fiera» y «llena de cólera» (30) lo insulta al considerarlo único responsable del fracaso $(31)^{62}$.

En este punto, la narración medieval concluía con la misma ingenuidad con la que había comenzado ${ }^{63}$, pero conociendo a Casti, el cuento no podía tener este brusco final sin una moraleja 'edificante' o sin que alguien obtuviera un resultado positivo. Y por eso, el modelo boccaccesco se va a ampliar con seis octavas más, en alguna de las cuales el personaje femenino cambia la actitud pasiva ${ }^{64}$ mantenida hasta entonces, por un cierto protagonismo más acorde con la situación, ya que parece no ser consciente en ningún momento de haber sufrido una auténtica agresión sexual, situación que ha soportado, por otra parte, sin experimentar o demostrar excitación alguna.

En las octavas añadidas por el escritor ilustrado notamos distintos tonos irónicos del narrador: empieza en la estancia 33 don Gianni con prudenza e zelo (v. 1) apaciguando la acalorada discusión matrimonial y con un reconciliador Pax vobis (v. 5), como inculca ai parrochi il vangelo (v. 3), les sugiere que «como cristianos verdaderos» (v. 7) tengan resignación, consejo ‘evangélico’ del que el párroco se burla, riéndose con la expresión dia-

\footnotetext{
${ }^{60}$ Todo está a punto de concluir «quando donno Gianni tiratolo indietro disse: 'Oimè, compar Pietro, che hai tu fatto? Non ti diss'io che tu non facessi motto di cosa che tu vedessi? La cavalla era per esser fatta, ma tu favellando hai guasta ogni cosa, né piú ci ha modo da poterla rifare oggimai» (BocCACCIO 1992: §20). Un crítico dice al respecto de este pasaje: «Donno Gianni non compie affatto il coito con Gemmata, anzi se ne ritrae proprio nel momento dell'orgasmo, cioè non approfitta affatto della situazione favorevole in cui è venuto a trovarsi» (BÀRBERI SQUAROTTI 1983: 187).

${ }^{61}$ Compárese el texto de la oct. 28 del Apéndice con la versión italiana: «E volto a compar Checco, 'oimè!' gli dice / 'Or che hai tu fatto? mentre al compimento / Le cose gían con esito felice / Per non aver taciuto anche un momento / Tutto hai guastato, e omai più non mi lice / Di nuovo incominciar l'incantamento / Per aver trasgredito al gran divieto / Con quel tuo favellar sciocco e indiscreto'».

${ }^{62}$ Esta reacción recalca el hecho de que a ninguno de los cónyuges se les puede pasar por la imaginación que el párroco los ha engañado; es más, parece que están convencidos de haber sido protagonistas de un ceremonial mágico fallido, y no de una escena erótica, creencia que, por otro lado, les va a permitir después seguir manteniendo con su invitado una relación amistosa.

${ }^{63}$ En Boccaccio, la joven Gemmata «dolente e malinconosa si rivestì, e compar Pietro con uno asino [...] attese a fare il suo mestiero antico; e con donno Gianni insieme n'andò alla fiera di Bitonto né mai piú di tal servigio il richiese» (BoCCACCIO 1992: § 24).

${ }^{64}$ En el relato de La Fontaine también había alguna modificación que aumentaba lo 'picaresco'; Pierre no sólo grita, sino que no puede impedir la situación y tira de la sotana de Messiere Jean para separarlo de su mujer, Magdeleine, cuya actitud ha ido cambiando con el desarrollo de los acontecimientos: desde el inicial pudor, es ella la que propone al cura que regrese diariamente para intentar nuevamente el hechizo, aunque una rápida y resuelta intervención del marido zanja el asunto evitando prolongar la embarazosa situación (LA FonTAINE 2002, vv. 158-184).
} 
lectal sotto i barbigi $(34$, v. 5), es decir, 'bajo los bigotes', mientras el traductor introduce otro matiz sarcástico lleno de cinismo: «el Cura, entre sí, admira su inocencia [la de ambos esposos]» $(34$, v. 5). Ante nuestra sorpresa, después de todo lo ocurrido, los dos hombres salen juntos de nuevo a 'mercadear', como si nada hubiera ocurrido, cargando «uno su yegua y otro su borrico / y se van a un vecino lugarcico» (vv. 7-8 ${ }^{65}$.

Pero la historia no termina ahí: a la noche siguiente, el Checco de Casti tiene ánimos para reintentar, sin testigos molestos, un nuevo 'acto mágico' con su esposa, tal y como creía haber aprendido de don Gianni (35). Pero entonces, la ironía utilizada hasta ahora se convierte casi en sangrante crueldad con la reacción de la mujer que, tras la reciente experiencia vivida con el 'mago', sí tenía ahora un punto de referencia diferente respecto de las aptitudes y 'medidas' de su esposo que había osado col piovan porsi a confronto $(36, v .8)$ con un sugerente y nada afectivo diminutivo: con quel codin, che appena è in ver palpabile $(37$, v. 3$)$. De nuevo la versión española se nos presenta más directa e hiriente con el marido (36), lo que la hace, si cabe, más cercana a un público femenino que podía divertirse y ensañarse en el ridículo de un machismo herido. Por eso, una vez que Checco se convence d'esser di coda appicatore inabile $(37$, v. 5) y de no ser capaz de poder competir con el «dicemisa» del irreverente traductor -a causa de su «colilla miserable / que apenas ni se toca ni divisa» (37, vv. 3-4)-66, el cuento concluye con un lieto fine, al menos para la campesina, que parece no mostrarse ya tan ingenua, pero sí repetidamente 'encantada', con las posteriores visitas del nuevo amante (oct. 38):

\begin{abstract}
Ni ya de ello se habló desde aquel día, Siendo lo más gracioso en la aventura Que desde entonces, cuando bien venía, La cola a la comadre aplicó el Cura, Pero sin alumbrar, cuando se hacía, Ni aún saverlo el Compadre. Y se asegura Que de ser Cita yegua no hablaron Pues con ser Checo buey se contentaron.
\end{abstract}
E non mai più parlò di cotal fatto; Ma l'aneddoto poi più singolare È che il piovan, come gli venne fatto, Spesso appiccò la coda alla comare, Senza cercar che intervenisse all'atto O fosse consapevole il compare; Ma non già più l'impegno egli contrasse Ch' ella in cavalla mai si trasformasse.

Para concluir con este comentario, se me plantea una última pregunta: ¿la metamorfosis ha fallado realmente, como se dice y se repite con insistencia en la narración? Es evidente que la respuesta tendría que ser afirmativa si pensamos que Zita no llegó nunca a transformarse en yegua, de lo que ni siquiera era menester hablar (v. 7); pero ese resultado, derivado de un engaño premeditado, lo sabíamos ya todos los lectores desde el principio de la narración, así como el propio don Gianni o las damas del siglo XVIII que escuchaban atentas a Casti. Sin embargo, si en vez de partir de un fraude entramos en el juego de un espectáculo de magia ¿acaso los magos no nos hacen ver aquello que ellos quieren o pretenden que veamos? Pues entonces, el piovan de nuestro cuento lo consigue plenamente: la pareja no se percata de la agresión sexual de la que ambos han sido objeto y, al mismo tiempo, creen lo que no es, es decir, están seguros de que han asistido a un

\footnotetext{
${ }^{65}$ La forma diminutiva de «lugarcico», además de rimar con «borrico», podría darnos una nueva pista de que el anónimo fuera de procedencia aragonesa, como su posible mentor parisino el embajador Azara.

${ }^{66}$ La resignación del marido burlado es realmente hiriente: «Checo que su impotencia ve palpable, / de que impidió el encanto al dicemisa, / Se cargó sobre sí toda la culpa / Y como mejor puede se disculpa» (37, vv. 5-8).
} 
encantamiento, aunque sin el resultado que esperaban: quien se ha 'metamorfoseado' en animal cuadrúpedo, es el marido, aunque sea en un humillante «buey». En este sentido, creo poder responder a mi pregunta anterior: el mago no ha fallado, así como tampoco su acto de magia.

Es muy probable que el desmesurado éxito que las novelle de Casti tenían entre las mujeres se debiera precisamente a que son ellas, pertenecientes a muy distintas clases sociales, las protagonistas directas o indirectas de unos argumentos donde el amor, la seducción, la sexualidad o la casuística conyugal y familiar siempre están presentes de una u otra manera. La mujer que el abate libertino defiende, admira y nos muestra no es que no sufra las presiones del varón de turno -sea padre, marido, amante o confesor- sino que con astucia e inteligencia intenta salir airosa de esa presión masculina 'institucionalizada' secularmente, sacando el mayor goce posible para ella misma. Y eso, en el fondo, es lo que le proporciona Casti a la Zita de nuestro relato: al ser el marido el ridiculizado, sabe que se asegura, aún más, la complicidad del público femenino ${ }^{67}$.

\section{REFERENCIAS BIBLIOGRÁFICAS}

ARCE MENÉNDEZ, Ángeles (1999): «La metáfora del usignolo: de la 'mano' de Boccaccio a la de Casti» en Amor y erotismo en la literatura, Salamanca, Hergar S.L.: 51-59.

—, (2000): «Reflexiones sobre la fecha de nacimiento de Giambattista Casti». Cuadernos de Filología Italiana, 7: 115-138.

_, (2003): «El mito de Prometeo y Pandora 'metamorfoseado' por Casti en un cuento del Settecento italiano». Epos. Revista de Filología (UNED), XIX: 259-276.

—, (2007): «Una traducción inédita castellana de las Novelle galanti de G. Casti» en La Traduzione della letteratura italiana in Spagna (1300-1939), a cura di Nieves Muñiz Muñiz, Firenze, Franco Cesati editore: 487-508.

BÀRBERI SQUAROTTI, Giorgio (1983): «Gli ammaestramenti di Dioneo» en Il potere della parola. Studi sul 'Decameron', Napoli, Federico \&Ardia: 174-192

BocCACCIO, Giovanni (1992): Decameron, a cura di Vittore Branca, Torino, Einaudi.

CASTI, Giambattista (1797): Novelle galanti dell' Ab.Casti divise in due volumi (18 novelle). In Milano, Nella Stamperia de' Patriotti d'Italia, Anno V. Repubb. (XIII: L'incantesimo, II: 77-89).

CASTI, Giambattista [1801-02]: Novelle di Giambatista [sic] Casti romano, (48 novelle). Parigi, Dalla Tipografia Italiana, Anno IX (Novella XLIV: L'Incantesimo, t. VI: 53-65).

DHTE (=Diccionario Histórico de la Traducción en España) [en prensa]. ARCE MENÉNDEZ, Ángeles «Casti, Giambattista» en Lafarga, F. y Pegenaute, L. (eds.), Madrid, Gredos.

GDLI (=Grande Dizionario della Lingua Italiana), (1961-2002). Diretto da Salvatore BATTAGLIA (poi da Giorgio BÀrberi SQUAROTTI), Torino: UTET.

FonTAINE, Jean De La (2002): Cuentos y relatos en verso, edición bilingüe y traducción de Miguel Ángel García Peinado, Madrid: Cátedra (el cuento de La yegua del compadre Pedro se encuentra en las pp. 654-665).

${ }^{67}$ La idea de complicidad con las mujeres estaba presente también en Boccaccio que, como es sabido, eran también las destinatarias del Decameron. En este cuento, que cierra la jornada novena, también se observa en las palabras con las que comienza la Conclusione: «Quanto di questa novella si ridesse, meglio dalle donne intesa che Dioneo non voleva, colei sel pensi che ancora ne riderà» (BocCACCIO, 1992: 1106). 
GUTHMÜLLER, Bodo (2002): «La metamorfosi fallita (Dec. IX, 10)» en Autori e lettori di Boccaccio. Atti del Convegno Internazionale di Certaldo (20-22 sett. 2001), a cura di Michelangelo Picone. Firenze, Franco Cesati editore: 195-207.

Nigro, Salvatore (1979): «Casti, Giambattista» en Dizionario Biografico degli italiani (DBI). Roma: Treccani, vol. 22: 26-36.

SuRDICH, Luigi (2004): «'La vanità delle cose' e le 'frondi di quercia: la nona giornata» en Introduzione al Decameron, a cura di M. Picone e M. Mesirca. Firenze: Franco Cesati editore, pp. 227-265 (especialmente «Le galline, le papere, la cavalla», pp. 249-253).

\section{APÉNDICE ${ }^{68}$}

\section{EL ENCANTAMIENTO Novela XLIV}

[f. 201 r.]

$1 \mathrm{a}$

Se acavó ya aquel tiempo, niñas mías,

En que se obraban los encantamientos,

$\mathrm{Y}$ en que dejaba sus tinieblas frías

El demonio, viniendo a hacer portentos;

En que las noches eran claros días

Y cambiaban los mismos elementos,

$\mathrm{Y}$ en que, por fin, con mágicas palabras

Se hacía andar a los astros como a cabras.

2a

Pero como savéis que estos engaños

Fueron del crédulo y ciego gentilisimo,

Y adoptados después por muchos años

Y aun hasta el día por el Cristianismo,

Os contaré de un Cura los amaños

Con que fingió mudar, por magicismo,

A una muger en yegua, y en vez de ello

Mudó al marido en un cabrón muy bello.

[f. $201 \mathrm{v}$. ]

$3 \mathrm{a}$

Havía un Cura en Barleta, cuya renta

A tres duros por mes nunca llegaba.

Tenía una yegua roja y macilenta,

La cual por ganar algo la alquilaba,

$\mathrm{O}$ bien con ella el mismo se presenta

En los mercados, do vendía y compraba

Ya higos secos, o pasas, o piñones,

Ya cevollas, pimientos, o melones.
$4 \mathrm{a}$

Si al derecho canónico se atiende

Sé que hacer esto a un Cura se le veda, Pero si el povre que comer no tiene

Con la necesidad no hay ley que pueda.

Si hubiere alguno que la tripa llene

Con los cánones solos, no se exceda;

Mas si no bastan, por ganar la vida,

Deve ser toda industria permitida.

$5 \mathrm{a}$

Para apartar a un Cura del negocio

Le ha de dar de comer su santo oficio.

Mucho más se deshonra el Sacerdocio

Por los que tienen pingue beneficio;

Y dormitando entre el placer y el ocio

Se revuelcan cual cerdos entre el vicio.

$\mathrm{Y}$ tal disparidad como lo es ésta

La equidad la abomina y la detesta.

[f. 202 r.]

$6 \mathrm{a}$

Pero allá se las hayan, que no quiero

Envenenar mi humor con tal idea;

Ni yo pretendo ser censor severo

Por más maldades que en el mundo vea.

Confío que hay un Dios que es justiciero;

Y por lo mismo sea lo que sea,

Y que esta bola ruede cual quisiere

Que yo a mi Cura voy porque no espere.

${ }^{68}$ Se reproduce íntegramente el texto del manuscrito que se encuentra en la Biblioteca Nacional de Madrid (Ms. 4084, ff. 201r.-207r.). Se conservan todas las variantes y fluctuaciones léxicas (laísmo, leísmo ...) y ortográficas (uso de $v / b, g / j, h \ldots$ ) del texto, pero se moderniza la acentuación y puntuación para facilitar su lectura. 
$7 \mathrm{a}$

Como andava, según antes decía,

Por las ferias y de uno a otro mercado, Muchísimas veces encontrar solía

A un paysano, que estaba dedicado

A la misma pequeña grangería

Con un mal borriquillo muy matado.

Era el tal hombre contrahecho y seco

Y le llamaban el Compadre Checo.

$8 \mathrm{a}$

Vivía con su muger en una aldea

Que Tres Santos se llama; era membruda

La muger, era joven y no fea,

Y se llamaba Cita Caramuda.

No hay cosa que uno y otro no la crea

Por difícil, en nada ponen duda;

De modo que a decir la verdad llana,

Eran dos burros en figura humana.

[f. 202 v.]

$9 \mathrm{a}$

Don Juan, que es como el Cura se llamaba,

Con el continuo verse y encontrarse

De tal modo con Checo se amistaba,

Que sin necesidad de convidarse

Uno en casa del otro se marchaba,

Como entre amigos suele acostumbrarse;

Se hacían los dos favor mutuamente,

Y se cedían las casas francamente.

$10^{69}$

En la de Checo solo un cuarto havía

Lleno de trastos, y en que estaba el lecho

En que con su muger Checo dormía;

Y una cuadrita, que el mismo había hecho

Para el burro; y allí cuando venía

El Cura, en un pesebre muy estrecho

Con paja y el manteo se forjaba

Un mal camastro, en que a dormir se echaba.

11

Y esto a pesar de la obsequiosa instancia

Que le hace al Cura de continuo Cita

Para que use su cama y de su estancia;

Pues que ella irá contenta con la Rita,

Su comadre y amiga de la infancia,

A dormir en la casa que ésta habita.

Pero nunca, por más que importunase,

Pudo lograr que el Cura lo aceptase.

\footnotetext{
${ }^{69}$ A partir de aquí usa el cardinal y no el ordinal.
}

[f. 203 r.]

12

Un día, pues, la dijo chanceando:

«Déjame en esta cuadra, Cita bella,

Y que aquí siga de mi encanto usando

Por el cual mudo en muy linda doncella

A mi yegua en el punto que lo mando,

Durmiendo y solazándome con ella,

Hasta que veo que se acerca el día

Y a la forma la vuelvo que tenía». 13

Maravíllase Cita, y cree cuanto

El Cura dice. Cuéntalo al marido,

Y le añade: «Si él es tu amigo, tanto

Como muchísimas veces te lo he oído,

¿Por qué no haces te enseñe el tal encanto

De que sacar podremos gran partido?

Pues ganarás el doble y te harás rico

Conmigo vuelta en yegua y el borrico».

14

«Y de vuelta a la noche en nuestra casa

Tornárasme en muger cual soy aora».

Checo, cuya idiotez no tiene tasa

A su muger creyó en la misma hora;

Y como su fortuna es tan escasa,

Por ver si de este modo la mejora,

Fue a Don Juan y le pide por Dios santo

Que a hacer le enseñe su precioso encanto.

[f. 203 v.]

15

Don Juan se admira, y ríe al escucharlo;

Le pretende apartar de tal locura,

Y no hay razón que baste a separarlo.

Nada omitió por conseguirlo el Cura,

Mas viendo no poder desengañarlo

Y que ya su elocuencia se le apura,

«Lo haré», le dice, «pues tu empeño veo,

Y que vencer no puedo tu deseo».

16

«Levantados mañana antes del día,

(Como regularmente hacer solemos)

Yo te haré conocer la amistad mía

$\mathrm{Y}$ a Cita vuelta en yegua la veremos.

Sabe, compadre, que esto no lo haría

A no ser la amistad que nos tenemos.

Mas devo hacerte una advertencia sola:

Que el gran misterio es aplicar la cola». 
17

Pasa la noche el matrimonio en vela

Teniendo por un siglo cada instante,

Tanto es lo que el encanto los desvela.

A decirle a Don Juan que se levante

Por la escalera el uno y otro vuela

Sin poder esperar que el gallo cante.

Él, que en camisa está, así se levanta,

$\mathrm{Y}$ con ellos al cuarto se adelanta.

[f. 204 r.]

18

Luego que suben, dice: «Aunque este arcano

A nadie revelarlo yo debiera,

De hacerlo ayer os dí palabra y mano,

Y aora voy a cumplir lo que ofreciera,

Pero devo instruiros de antemano».

La luz da a Checo, y con la voz severa

Le dice: «Estate aquí sin movimiento

Pues de otro modo no hay encantamiento».

19

«Desde aí observa cuanto a mí hacer vieres,

$\mathrm{Y}$ aprende de memoria cuanto diga;

Pero por más que veas o que oyeres

A callar y estar quieto te se obliga.

Y ni aún alientes, si esto hacer pudieres,

$Y$ quieres que el encanto se consiga.

Mas sovre todo pide al cielo santo

Que se aplique la cola sin quebranto»

20

Y luego hace que Cita en cueros puesta

$\mathrm{Y}$ en cuatro pies, cual si una burra fuese,

Oiga lo que la dice y amonesta,

Y es: que por más que vea o que sintiese

Se guarde de decir mi boca es ésta,

$\mathrm{Y}$ hacer le deje aunque haga lo que hiciese.

Da en derredor tres vueltas, y entretanto,

Con estas voces principió el encanto.

[f. 204 v.]

21

«Vosotros ¡o Astaroht, Nesroch, Beliam!

Dadme atención, y que mi voz os mueva.

Yo os conjuro por la alma de Abraham

A vosotros, que hicisteis la gran prueva

De que hablase la burra de Balaam

Y a Navuco de buey dar forma nueva.

¡Espíritus de figura y sexo informe

Haced que Cita en yegua se transforme!».
22

Tócala luego la caveza y rostro, y dice:

«Sea esta caveza y rostro de una yegua».

Toca lomos y piernas luego, y dice:

«Sean estas piernas y lomo de una yegua».

Después tocóla el pecho y la barriga, y dice:

«Sea este pecho y barriga de una yegua».

$\mathrm{Y}$ así las demás partes recorriendo

Iba la misma frase repitiendo.

23

El viril miembro en esta bataola

$\mathrm{Y}$ con tanto lascivo tocamiento

Se engríe, se endurece, y se enarbola;

$Y$ no faltando ya al encantamiento

Sino tan sólo el aplicar la cola,

Se alza de la camisa el faldamento,

El dardo envayna, y dice sin mas tregua:

«Que sea esto, pues, la cola de la yegua».

[f. 205 r.]

24

Se ve tal vez en la pradera hervosa

Cuando se va por ella paseando

Cavallo, que a carrera impetuosa

Y de lujuria lleno, va bufando

$\mathrm{Y}$ se echa encima de la yegua hermosa

Que en la misma pradera está pastando,

Y que la aldeanilla algo escondida

Muerde el lavio y atisva enardecida.

25

Mas Checo no es así; pues aunque ha estado

Hasta entonces atento sin moverse,

Al ver como la cola se ha aplicado,

Y creyendo que así no devía hacerse,

O no puede, o no quiere estar callado,

Aunque vaya el encanto a deshacerse.

$Y$ vuelto al Cura dice en tono fiero:

«Yo no quiero esa cola, no la quiero».

26

Cual niño, a quien en chanza se le quita

El higo o pera que antes le habían dado,

Que al pronto ríe, y juguetón te imita,

Pero que al ver tomar de ella un bocado,

Se enfurece, patea, llora y grita,

Y no puedes dejarle sosegado

Sin dársela otra vez, pues no se fía

$\mathrm{Ni}$ a juego tiene ya lo que tenía.

[f. $205 \mathrm{v}$. 
27

Checo deja la luz, y al Cura viene,

A quien, para apartarle, el brazo tira;

Mas éste sovre Cita se mantiene

Y más se encorva, empuja, aprieta, estira,

Hasta que el gran placer término tiene

Y de la húmeda vayna lo retira

El generante miembro, aún goteando

El suco radical que estava echando.

28

Y vuelto a Checo: «¿Que has hecho cuitado?»

Le dice: «interrumpir el cumplimiento

De obra que tanta pena me ha costado,

Y esto, por no callar otro momento.

Mas tú lo pierdes; pues a mí no es dado

El dar principio a un otro encantamiento;

En pena de no haver obedecido

Y hablar sin que se huviese concluido».

29

«Todo eso está muy bien», responde Checo,

«Mas yo allí aquella cola no quería;

Porque, amigo Compadre, en aquel hueco....

Y al fin, si el aplicarla se debía

¿No pudiera yo hacerlo que no peco?

¿Junto a Usted aplicarla no podía?»

«Compadre», dijo el Cura con presteza,

«Siempre acava el encanto quien lo empieza».

[f. $206 \mathrm{r}$.]

30

«A más que en esto de aplicar la cola

Se ha de saver el punto y la manera,

$\mathrm{Ni}$ se aprende con verlo una vez sola.

¿Ni cómo el aplicarla bien pudiera

El que nunca encantó, vio, ni aplicóla?»

Y Cita puesta en pie y hecha una fiera

Porque el encantamiento se ha impedido,

Dice llena de cólera al marido:

31

«Estoy por arañarte, majadero,

Que has sido y serás bestia hasta que mueras.

¿No valía más morirte aquí primero

Que tal rebuzno en contra nuestra dieras?

¿Dime, animal (porque saverlo quiero)

Yegua sin cola has visto ni la vieras?

Pobre eres en verdad; pero cien veces

Más pobre que aora estás, estar mereces».
32

«Vamos, que yo de colas sé una miaja» Checo responde, «y el compadre Cura, Según yo entiendo, la aplicó muy baja; Pues cola bajo el ano desfigura».

«Y aunque eso sea» (así Cita le ataja)

«¿No es una indiscreción y una locura

Por tres dedos arriba o más abajo

El echar a perder todo el trabajo?»

[f. $206 \mathrm{v}$. ]

33

Don Juan, que es hombre de prudencia y celo

Para que el matrimonio se aquietase

Se puso en medio y dijo con anhelo,

Cual si a sus feligreses predicase:

«Pax vobis. Y saved, no quiso el cielo

Que esta muger en yegua se mudase,

Por lo que, cual Cristianos verdaderos,

Debéis a sus decretos someteros».

34

Así la riña, pleyto y diferencia

Se acavó entre los dos enteramente;

Resignan uno y otro su obediencia

$\mathrm{Y}$ de paz se revisten santamente.

El Cura, entre sí, admira su inocencia;

Baja a cargar con Checo juntamente

Uno su yegua, y otro su borrico

$Y$ se van a un vecino lugarcico.

35

Vuelto a su casa Checo, con su esposa

Hablaba por la noche del encanto,

Y la dice: «¿Apuestas a una cosa?

A que yo como el Cura hago otro tanto

$\mathrm{Si}$ en cuatro pies te pones Cita hermosa?»

Pónela con efecto, y entretanto

Que la cola la aplica, la decía:

«¿Lo hacía así el Cura? Dime Cita mía».

[f. 207 r.]

36

Mas sea que él sin vigor se la aplicase,

O que delgada y floja ella encontróla,

O que la de Don Juan más la gustase,

O que variando el gusto se acrisola,

Cita le dijo aún antes que acavase:

« $\mathrm{O}$ qué valiente aplicador de cola!

¡Qué aire se quiere dar de experto y diestro

Comparándose al Cura que es Maestro!» 
37

«iSería por cierto yegua despreciable Que a todos excitara a burla y risa

Teniendo esa colilla miserable Que apenas ni se toca ni divisa!» Checo que su impotencia ve palpable, De que impidió el encanto al dicemisa, Se cargó sobre sí toda la culpa, $\mathrm{Y}$ como mejor puede se disculpa.
38

Ni ya de ello se habló desde aquel día, Siendo lo más gracioso en la aventura Que desde entonces, cuando bien venía, La cola a la comadre aplicó el Cura, Pero sin alumbrar, cuando se hacía, Ni aún saverlo el Compadre. Y se asegura, Que de ser Cita yegua no hablaron Pues con ser Checo buey se contentaron. 